\title{
AGROECOLOGIA: UMA CIÊNCIA INTERDISCIPLINAR
}

\author{
Tábata Morena Rodrigues Saragoso, UFFS ${ }^{1}$ \\ Luana Garcia Machado, UFFS ${ }^{2}$ \\ Edith Geraldine Mareco Garcia, UFFS ${ }^{3}$
}

\begin{abstract}
RESUMO. O objetivo do trabalho foi realizar uma revisão bibliográfica sobre a temática da Agroecologia enquanto um enfoque científico interdisciplinar no âmbito da teoria e prática, considerando sua vocação para superar o paradigma da ciência moderna e transformar as relações socioculturais, econômicas e ambientais do meio rural.
\end{abstract}

Palavras chave: Agricultura; Desenvolvimento Rural; Paradigma científico.

\section{AGROECOLOGY: AN INTERDISCIPLINARY SCIENCE}

\begin{abstract}
The objective of this work was to carry out a bibliographical review on the subject of Agroecology as an interdisciplinary scientific approach in the scope of theory and practice, considering its vocation to overcome the paradigm of modern science and to transform the socio-cultural, economic and environmental relations of the rural environment.
\end{abstract}

Keywords: Agriculture; Rural Development; Scientific Paradigm.

\section{AGROECOLOGÍA: UNA CIENCIA INTERDISCIPLINAR}

Resumen. El objetivo del trabajo fue realizar una revisión bibliográfica sobre la temática de la Agroecología como un enfoque científico interdisciplinario en el ámbito de la teoría y práctica, considerando su vocación para superar el paradigma de la ciencia moderna y transformar las relaciones socioculturales, económicas y ambientales del medio rural.

Palabras clave: Agricultura; Desarrollo Rural; Paradigma científico.

\footnotetext{
1 Acadêmica do curso de Agronomia com Ênfase em Agroecologia na Universidade Federal da Fronteira Sul - UFFS Campus de Cerro Largo/RS. E-mail: tabatasaragoso@gmail.com

2 Acadêmica do curso de Agronomia com Ênfase em Agroecologia na Universidade Federal da Fronteira Sul - UFFS Campus de Cerro Largo/RS. E-mail: 1.g.machado@ hotmail.com

3 Acadêmica do curso de Agronomia com Ênfase em Agroecologia na Universidade Federal da Fronteira Sul - UFFS Campus de Cerro Largo/RS. E-mail: edith-mareco@ hotmail.com
} 


\section{Introdução}

Com o discurso ideológico de erradicar a fome mundial pelo aumento da produção de alimentos, a revolução verde teve papel chave no estabelecimento do modelo de agricultura convencional com a aplicação de pacotes tecnológicos padronizados e inserção do capital no campo através do agronegócio. Todavia, quase meio século depois, $11 \%$ da população mundial ainda passa fome (FAO, 2017), a desigualdade socioeconômica no meio rural só cresce e enfrentamos problemas ambientais ocasionados pelo uso desenfreado de agrotóxicos.

Ao invés de apenas gerar novas tecnologias que solucionem os problemas criados pela agricultura convencional sem transformar suas raízes, ou seja, as bases epistemológicas do conhecimento científico moderno, muitos cientistas das mais diversas áreas de conhecimento apostam na Agroecologia como um novo paradigma emergente capaz de superar as contradições do agronegócio e modificar as relações socioculturais, econômicas e ambientais a partir de um enfoque científico que integra as disciplinas de âmbito agronômico, ecológico, social, político, econômico, pedagógico, etc., com os princípios das agriculturas tradicionais através do resgate dos saberes populares.

Não obstante, a Agroecologia é comumente reduzida à lógica produtivista pela sua caracterização enquanto um modelo de produção ou determinada técnica agrícola "sustentável", o que para Caporal e Costabeber (2002), mascara a sua real potencialidade de apoiar processos de desenvolvimento rural. Desta forma, para melhor entendimento do seu significado, faz-se necessário recorrer a um aporte de diferentes disciplinas para compreender o funcionamento dos ciclos minerais, as transformações de energia, os processos biológicos e as relações socioeconômicas como um todo na análise dos diferentes processos que intervêm na atividade agrícola (LEFF, 2002).

\section{Consolidação do capital no campo e crise socioambiental}

A revolução verde foi o ápice da consolidação do capitalismo no campo. Através do discurso ideológico de desenvolvimento econômico do meio rural e fim da fome mundial, ocorreu a transição dos modelos de agricultura tradicionais para os ditos "modernos", que se baseavam na aplicação de pacotes tecnológicos padronizados com o 
uso intensivo da terra, sementes modificadas, maquinários, insumos químicos e novas tecnologias em todas as fases da produção (GABOARDI; CANDIOTTO, 2015).

No Brasil, a revolução verde tomou força no final da década de 1960 pelos incentivos do regime civil militar para barrar os projetos de reforma agrária. Esse processo foi chamado por muitos críticos de "modernização conservadora", pois não houve mudanças na estrutura fundiária do país, que se manteve estruturada no latifúndio. Com a adoção das políticas neoliberais a partir de 1990, o país investe na industrialização das atividades agrícolas e especializa sua produção de grãos para fins de exportação, fortalecendo assim o agronegócio.

Como consequência da adoção deste modelo de produção agrícola, houve significativo aumento do êxodo rural e a acentuação dos conflitos por terra, uma vez que os incentivos financeiros privilegiam os latifundiários em detrimento dos agricultores familiares e camponeses. Com relação aos impactos ambientais causados pelo agronegócio, destacam-se as consequiências do uso intensivo de agrotóxicos: a contaminação e compactação dos solos, que geram perda progressiva da microfauna e da fertilidade, e favorecem os processos de salinização e erosão; a poluição dos rios, cursos d'águas e lençóis freáticos; a contaminação dos animais e pessoas e a perda da biodiversidade dos ecossistemas.

Em virtude dos impactos da ação humana sobre a natureza e o meio ambiente, evidencia-se a ideia de que passamos por uma crise socioambiental (GABOARDI; CANDIOTTO, 2015). As contradições do agronegócio levaram ao seu esgotamento, e as buscas por alternativas contra a hegemonia do capital no campo encontram na Agroecologia uma práxis interdisciplinar onde suas perspectivas de validação dependem de sua articulação em torno de um novo paradigma científico de produção (LEFF, 2002).

\section{Agroecologia: um enfoque científico interdisciplinar}

O principal impacto do desenvolvimento sustentado pela racionalidade econômica para a ciência foi o estabelecimento de um paradigma fundamentado na fragmentação e reducionismo do conhecimento. Essa lógica objetivista auxiliou no avanço de uma consciência social patriarcal, consumista, individualista, autoritária e excludente, que Morin (1998) chama de "situação paradoxal, pois, o desenvolvimento 
do conhecimento instaura a resignação à ignorância e o da ciência significa $o$ crescimento da inconsciência”.

Diante deste cenário caótico, onde "a técnica produzida pelas ciências transforma a sociedade, mas também, retroativamente a sociedade tecnologizada transforma a ciência” (MORIN, 1998), é necessário romper este ciclo e transformar radicalmente as estruturas do sistema. A saída para o mundo cercado e esgotado do nosso tempo não está em aferrar-se às normas do dogma produtivista, senão em transcendê-las através de um novo saber (LEFF, 2002), com abordagem holística, não apenas no que concerne às questões ambientais, mas, sobretudo às questões humanas (JESUS, 2005).

O movimento em torno de formas não-convencionais de agricultura remonta ao início da agricultura industrial (JESUS, 2005). No Brasil, o debate sobre "agriculturas alternativas" se fortalece a partir de 1980, impulsionado por estudantes e profissionais da área da agronomia auto organizados na Federação de Estudantes de Agronomia do Brasil (FEAB) e Federação das Associações de Engenheiros Agrônomos do Brasil (FAEAB), através dos Encontros Brasileiros de Agricultura Alternativa (EBAA’s).

Inicialmente a Agroecologia foi denominada como "agricultura alternativa", devido à falta de outro termo à época que fosse capaz de englobar a lógica de uma abordagem holística, sistêmica, contextualizadora, subjetiva e pluralista, nascida a partir das culturas locais (GUZMÁN, 2001) com caráter de apoiar o processo de transição do modelo de agricultura convencional para estilos de agriculturas de base ecológica ou sustentáveis (CAPORAL; COSTABEBER, 2002). Após o avanço nos debates sobre seus princípios epistemológicos, adotou-se o termo Agroecologia devido ao estreitamento entre as disciplinas de Agronomia e Ecologia.

Portanto, a Agroecologia pode ser definida como "um novo paradigma produtivo, a integração de ciências, técnicas e práticas" (LEFF, 2002) e também como "uma ciência com campo de conhecimento de caráter multidisciplinar" (CAPORAL; COSTABEBER, 2002). Os autores concordam que a Agroecologia apresenta uma série de princípios, conceitos e metodologias capaz de prover uma análise sistêmica e holística do conjunto de relações e transformações nos agroecossistemas.

$\mathrm{Na}$ busca pela superação do paradigma da ciência moderna, muitos cientistas apostam na Agroecologia como proposta contra hegemônica ao modelo agrícola 
convencional, com potencial de resgate e reconhecimento das agriculturas tradicionais e saberes populares, e como uma ferramenta para a auto-subsistência e a segurança alimentar das comunidades rurais (LEFF, 2002) a partir de um enfoque científico e interdisciplinar, que integra princípios agronômicos, ecológicos e socioeconômicos.

A Agroecologia se encontra em um campo de disputa sociocultural e política (AGUIAR, 2010), o que reafirma seu caráter científico já que para Morin (1998) “o conflito das ideologias e pressupostos metafísicos é condição sine qua non da vitalidade da ciência”. Segundo Guzmàn Casado et al. (2000, p. 81, apud JACOB, 2011, p. 34) "reflexões teóricas oriundas de distintas disciplinas têm contribuído para conformar seu atual corpus teórico e metodológico" através da desconstrução dos pressupostos valorativos fixados na ciência moderna e construção de uma base dinâmica de conceitos a partir da reorientação de teorias, correntes e pensamentos científicos que colocam a Agroecologia como peça central no processo de desenvolvimento do conhecimento. Um exemplo a ser citado é o de Silva Neto (2013), que parte da premissa que para consolidar o caráter emancipatório da Agroecologia é preciso considerá-la no campo da complexidade.

No campo da ação a Agroecologia vem sendo semeada em todas as regiões do país através de esforços de movimentos sociais do campo que se apropriam de sua abordagem interdisciplinar para tratar temas que geralmente são ignorados pela agricultura convencional, como os problemas socioculturais do meio rural. Como exemplo é possível citar as experiências realizadas pelo Movimento dos Trabalhadores Rurais Sem Terra (MST) e o Movimento das Mulheres Camponesas (MMC): o MST adotou a Agroecologia como bandeira e a inseriu nos debates e ações de reforma agrária, utilizando-a como base para promover uma agricultura que garanta soberania alimentar, valorize o papel e a cultura do camponês, reduza custos e crie empregos; já o MMC aponta a importância da Agroecologia para o empoderamento e independência financeira das mulheres camponesas, e seu potencial de diminuir a desigualdade de gênero enfrentada por elas.

\section{Considerações finais}

O agronegócio é reflexo do atual paradigma científico que se baseia em técnicas produtivistas que fragmentam e reduzem o conhecimento. É possível concluir que 
enfrentamos o esgotamento deste modelo de produção agrícola devido aos impactos ambientais provocados pelas suas técnicas agressivas e pela crescente desigualdade socioeconômica no meio rural.

Movimentos sociais, profissionais de diversas áreas, organizações não governamentais e instituições de ensino, pesquisa e extensão apostam no enfoque científico e na abordagem interdisciplinar da Agroecologia como um paradigma emergente com capacidade de transformar as relações socioculturais do campo e de superar as contradições econômicas e ambientais do agronegócio.

Por fim, é importante defender a Agroecologia enquanto ciência interdisciplinar e não permitir sua redução a meras práticas agrícolas. Sua apropriação deve ser feita por todas e todos aqueles que não se sentem contemplados com as relações sociais baseadas na racionalidade econômica tecnicista e produtivista, e buscam a superação do paradigma científico e a transição para uma sociedade sustentável.

\section{Referências}

AGUIAR, M. V. A. Educação em Agroecologia: que formação para a sustentabilidade? In: Revista Agriculturas: experiências em agroecologia, Rio de Janeiro, v. 7, n. 4, p. 4-6, dez. 2010.

CAPORAL, F. R.; COSTABEBER, J. A. Agroecologia. Enfoque científico e estratégico. Agroecologia e Desenvolvimento Rural Sustentável, Porto Alegre, v. 3, n. 2, p. 13-16, abr./jun. 2002.

FAO; IFAD; UNICEF; WFP; WHO. The State of Food Security and Nutrition in the World 2017: Building resilience for peace and food security. Rome, 2017.

GABOARDI, S. C.; CANDIOTTO, L. Z. P. O caráter interdisciplinar e o potencial transformador da Agroecologia. In: XI Encontro Nacional da Associação de Pósgraduação e Pesquisa em Geografia, 2015, Presidente Prudente, SP. Anais do XI ANPEGE: A diversidade da Geografia brasileira: escalas e dimensões da análise e da ação. Dourados, MS: UFGD Editora, 2015. p. 6744-6757.

GUZMÁN, E. S. Uma estratégia de sustentabilidade a partir da Agroecologia. Agroecologia e Desenvolvimento Rural Sustentável, Porto Alegre, v. 2, n. 1, jan./mar. 2001.

JACOB, L. B. Agroecologia e universidade: entre vozes e silenciamentos. 2011. 222 f. Tese (Doutorado em Ciências), Universidade de São Paulo, Piracicaba, SP, 2011.

JESUS, E. L. de. Diferentes Abordagens de Agricultura Não-Convencional: História e Filosofia. In: AQUINO, A. M. de; ASSIS, R. L. de. (Ed.). Agroecologia: Princípios e 
Técnicas para uma Agricultura Orgânica Sustentável. Brasília, DF: Embrapa Informação Tecnológica, 2005. p. 21-48.

LEFF, E. Agroecologia e saber ambiental. Agroecologia e Desenvolvimento Rural Sustentável, Porto Alegre, v. 3, n. 1, p. 36-51, jan./mar. 2002.

MORIN, E. Ciência com consciência. 2. ed. Rio de Janeiro: Bertrand Brasil, 1998. 350 p.

SILVA NETO, B. Agroecologia, ciência e emancipação humana. Revista Brasileira De Agroecologia, v. 8, n. 1, p. 3-17, 2013. 